\title{
Dwelling within the fourth industrial revolution: organizational learning for new competences, processes and work cultures
}

\author{
Silvia Ivaldi \\ Department of Human and Social Sciences, University of Bergamo, \\ Bergamo, Italy \\ Giuseppe Scaratti \\ Department of Human and Social Sciences and Psychology, University of Bergamo, \\ Bergamo, Italy, and \\ Ezio Fregnan \\ Department of Psychology, Catholic University of the Sacred Heart, \\ Piacenza, Italy
}

\begin{abstract}
Purpose - This paper aims to address the relevance and impact of the fourth industrial revolution through a theoretical and practical perspective. The authors present both the results of a literature review, highlighting the new competences required in innovative workplaces and a pivotal case, which explores challenges and skill models diffused in industry 4.0, describing the role of proper organizational learning processes in shaping new work cultures.

Design/methodology/approach - The paper aims to enhance the discussion around the 4.0 industrial revolution addressing both a theoretical framework, valorizing the existing scientific contributes and the situated knowledge, embedded in a concrete organizational context in which the fourth industrial revolution is experienced and practiced.

Findings - The findings acquired through the case study endorse what the scientific literature highlights about the impact, the new competences and the organizational learning paths. The conclusions address the agile approach to work as the more suitable way to place humans at the center of technological progress.

Research limitations/implications - The paper explores a specific organizational context, related to a high-tech multinational company, whose results illustrate the empirical evidence sustaining transformations in the working, professional and organizational cultures necessary to face the challenges of the fourth industrial revolution. The research was conducted with the managers of an international company and this a specific and limited target, even though relevant and interesting.
\end{abstract}

(c) Silvia Ivaldi, Giuseppe Scaratti and Ezio Fregnan. Published by Emerald Publishing Limited. This article is published under the Creative Commons Attribution (CC BY 4.0) licence. Anyone may reproduce, distribute, translate and create derivative works of this article (for both commercial and non-commercial purposes), subject to full attribution to the original publication and authors. The full terms of this licence may be seen at http://creativecommons.org/licences/by/4.0/legalcode

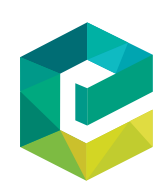

Received 28 July 2020 Revised 13 March 2021 Accepted 23 March 2021 
Practical implications - The paper connects the case with the general scenario, this study currently faces, to suggest hints and coordinates for crossing the unfolding situation and finding suitable matching between technological evolution and the development of new work and professional cultures and competences.

Social implications - Due to the acceleration that the COVID-19 has impressed to the use of digital technologies and remote connexion, the paper highlights some ambivalences that the quick evolution of the new technologies entails in relation to work and social conditions.

Originality/value - The opportunity to match both a literature analysis and an in-depth situated case study enhances the possibility to achieve a more articulated and complex view of the viral changes generated in the current context by the digitalization process.

Keywords Competences, Skills, Culture, Organizational learning, Fourth industrial revolution, Technological innovation, Work and organizational culture

Paper type Case study

\section{Introduction}

The world is facing huge changes in culture, society and economy which are direct consequences of the digital revolution, that is depicting a new dwelling place where we are challenged to live. Technologies play an essential role in the upcoming fourth industrial revolution, discussed on a global scale, as when the World Economic Forum (WEF) focused its attention on it in 2016 (WEF, 2016). This phenomenon is represented by an unprecedented level of automation and connectivity, based on artificial intelligence, big data, robotics and the internet of things (IoT). Such a modified scenario is changing our lives as social beings, citizens, consumers, professionals and practitioners inside the so-called Industry 4.0, characterized by a new conception of the manufacturing processes, decentralized and adopting systems based on the information and communications technologies (Park, 2017).

Even though we are aware of the drivers of innovation (automation and connectivity), we are still far from a full understanding of the potential of this revolution in terms of both speed and extent. We can for instance take into consideration the almost unlimited possibilities of connecting billions of people by means of mobile devices, generating an unprecedented capacity for processing, archiving and accessing information (Schwab, 2016).

As the first industrial revolution different phases changed our society, from rural/feudal to industrial/capitalist and then to industrial/tertiary. Automation and connectivity always played a crucial role in this process, along with the spasmodic search for increased productivity.

Many debates addressed the current situation, discussing its own features and highlighting both the advantages and risks it implies.

The first widely analyzed element is the very nature of this era and its orientation (Park, 2017). Most of the worldwide economic community defines the current scenario as the fourth industrial revolution, but several established authors argue that just now we are living the first effects of the Third Industrial Revolution and soon we will experiment with its evolution (Rifkin, 2016; Blinerd, 2006).

According to Klaus Schwab, we are going to experience a revolution and not just an evolution on the basis of three criteria: speed (due to today's world, which is extremely heterogeneous and interconnected because of the increasingly performing technologies), range and intensity (combining different technologies the individual constantly changes at economic, corporate and social level); impact on the systems (whole systems can be transformed by such a radical change, including countries and the global society itself) (Schwab, 2016). 
A second element at the core of the debate on the fourth industrial revolution is the one between the so-called optimist and pessimist authors. The former group believes that in the long term the opportunities generated by new technologies will minimize the damages caused in the short term. Pessimists are convinced that we are facing a vertiginous free-fall toward the end of work and an undeniable consequent increase of inequalities at both global and intra-national levels (MacCarthy, 2014).

Such first elements of discussion let many other issues emerge in the literature brings to light both concerns and opportunities related to the upcoming revolution. The main components resonating in this context include automation and connectivity again (Schwab, 2016; Park, 2017; Prisecaru, 2016; Caravella and Menghini, 2018; Corazza, 2017; Blinerd, 2006), as well as all those technologies whose development is opening the way for progress and countless new possibilities, following an exponential growth model (Caruso, 2017; Schwab, 2016).

The impact interests the physical area (e.g. autonomous vehicles, three-dimensional printers and advanced robotics), the digital area (e.g. IoT, platforms and IoS) and the biological area (e.g. artificial intelligence for genetics, biology and related applications).

Currently, technological innovations have strongly influenced every aspect of both economic and social life, impacting basic mechanisms as the development of the demand, as well as the accumulation of capital and the generation of employment (Schwab, 2016).

Finally, the current scenario related to the COVID-19 pandemic has boosted the use and diffusion of technological devices (remote working, smart working, apps, analytics, etc.), answering the need to tackle the dramatic worldwide emergency we must face (Carroll and Conboy, 2020).

Hence, the need for a deeper understanding of the challenges implied in becoming competent dwellers of the fourth industrial revolution's scenario, specifically pointing out, in this contribution, the solicitations at stake in the organizational learning processes oriented to the achievement of new competences and work cultures.

The paper aims to enhance the discussion around the 4.0 industrial revolution and its implications, seeking to explore the following research questions:

$R Q 1$. What is the scientific contribution, moving from an interdisciplinary lens (socioeconomic, managerial, work and organizational psychology fields), about the relevance and impact of the fourth industrial revolution?

$R Q 2$. What are the main implications for organizational learning processes?

RQ3. What new approach to work, new competencies and cultural change need to be promoted due to the incoming technological and social scenario?

Seeking to face such questions, we will address both a theoretical framework, valorizing the existing scientific contributions through a literature review and the situated knowledge, embedded in the concrete organizational contexts, studying a specific workplace in which the fourth industrial revolution is experienced and practiced.

The paper unfolds as follows: first, we highlight the more relevant results of a literature review we made to provide a deeper exploration of the scientific contribution around the fourth industrial revolution, as a macro lens for reading the phenomenon from an interdisciplinary perspective in Section 2. Then we offer an account of the organizational learning implications that are required in this emerging work landscape, as a meso level viewpoint for acknowledging relevant shifting points in innovative workplaces in Section 3. After that we turn to a case study drawn from the field research, discussing its emblematic relevance in shaping new competences, processes and organizational cultures, as a micro-level stance for 
JWL 34,1

understanding the intertwined and embedded features of competence development in the emerging work environments in Section 4. We conclude by connecting the case with the general scenario we currently face, to suggest hints and coordinates for crossing the unfolding situation and finding suitable matching between technological evolution and pandemic emergency in Section 5 .

\section{Fourth industrial revolution in the scientific debate: a macro-level perspective}

Taking into consideration the context illustrated in the introduction, a systematic literature review (Tranfield et al, 2003) has been conducted, following the Alvesson and Sandberg perspective (Alvesson and Sandberg, 2013), to provide an overview of the available scientific contributions concerning the debate on the fourth industrial revolution, trying to understand orientations and relevant topics.

The main objectives of the review have been:

- Mapping the contributions bringing to light the main focuses of the fourth industrial revolution;

- Providing an exhaustive analysis of the selected contributions, distinguishing the main hypothesis at the basis of the current debate to investigate both its potential and challenges; and

- Identifying the different perspectives adopted in literature and the different interpretations of the phenomenon.

The research process has been carried out using both databases and additional "open" sources. The considered time frame has been May 2008-May 2018. The used databases have been SCOPUS, ProQuest, JSTOR, Rivisteweb and Google Scholar, starting from some keywords to identify the potentially interesting articles for the study. The keywords used were: "fourth industrial revolution," "industry 4.0," "digital transformation," "artificial intelligence" and "robot."

A first selection phase was completed using as inclusive criteria: article peer-reviewed; with descriptions and interpretations of the fourth industrial revolution; with analysis of the impact of the digital transformation. Additional criteria to select the contributions have been that they had to belong to one of the following categories: scientific articles, documents of conferences about this issue, chapters of texts quoted more than once in the other articles. We identified the first sample of 117, among which 57 were excluded after abstract and title reading, while 60 full-text articles were assessed for eligibility as potentially interesting works, of which 29 articles have been the object of a deep qualitative analysis of their contents. A relevant turning point in this assessing process was the publication of Klaus Schwab's book "The fourth industrial revolution" in 2016, which catalyzed the interest of the scientific community in all its implications (social, economic and organizational). The articles have been classified by year of publication, title, authors, focus and disciplinary field.

From the analysis of such contributions, we identified three leading topics: impact of the fourth industrial revolution on society as a whole; labor market and related technological unemployment; new competences for coping with the industrial revolution.

\subsection{Impact on society}

With relation to the impact on society, organizations and institutions, the literature analyzed tries to predict the future effects of the revolution on the different social systems. The 
awareness of the epochal change that we are going to live must serve to face its challenges, limiting the damage as much as possible and fully exploiting its potential (Daemmrich, 2017; Makridakis, 2017; Schwab, 2016; Chung and Kim, 2016).

The literature review identifies both potentials [closeness and connection between people and institutions (hierarchies and bureaucracy will constitute a limit to production and diffusion of knowledge) and more aware and autonomous people and workers; more skilled and talented people] and risks [improvement of the gap due to the unequal distribution of resources and improvement of precariousness]. The potential of the new wave of technologies is to increase the level of productivity and growth but also to respond to global issues such as environmental sustainability. The risks concern the increase in social inequalities, the worsening of work conditions and technological unemployment (Chung and Kim, 2016; Schwab, 2016; Park, 2017; Garrett, 2013).

Indeed, the continuous technological innovation takes place within a broader transformation of the economy as a whole, in an unfolding process of evolution from traditional models [global competition, mass customization, neo-liberalistic approaches in conceiving management and organizational processes (Bondarouk and Brewster, 2016; Janssens and Steyaert, 2009)], toward a development of services and new ways of sharing, circular and generative economy (Stiegler, 2014; Butera, 2017), supported by digital technologies.

For what concerns the productive organizations, on the one hand, technologies such as artificial intelligence will most likely increase the number of automated jobs and consequently reduce the demand for work; on the other hand, the efficient functioning of new businesses will require highly qualified and talented employees. The management of talented individuals capable of implementing innovative ideas and strategies will become a real competitive advantage (Makridakis, 2017). The centrality of talent requires a revision of organizational structures as flexible hierarchies, new ways to evaluate and reward performance and new strategies to attract and retain qualified personnel will become essential aspects for a successful business (Schwab, 2016). Human capital and technological innovation will play the most important role in the success of companies (Park, 2017), while the new employment contract will include continuing training as worker's rights.

More in general, the digital transformation entails a revolution in the socio-cognitive models of our realities both in the individual and in the interactional and collective horizons. Regarding the social sphere, we are experiencing a real paradigm shift that involves the way we work, communicate and access information but also the way we express ourselves and spend our free time (Schwab, 2016). We live perpetually connected to the network and this is paradoxically limiting communication and social relations. Hence, the need to acquire skills to dwell in a hybrid world in which it will not always be obvious to understand the nature of the interlocutors (human or artificial) and the environments (real or virtual) in which relationships are realized. Hence, also the need to rethink and redefine some typically social attitudes such as delegation, control, trust, autonomy, responsibility, dealing with the society of the future as "Internet society" (Bakardjieva, 2005), "network society" (Castells, 1996), "Knowledge-based society" (Stehr, 1994), "cybersociety" (Jones, 1998). Living in a knowledge-intensive society requires relevant learning processes at both individual and collective levels.

\subsection{Labor market and technological unemployment}

About the newly emerging work conditions, the great challenge we are going to face in the labor market requires an in-depth analysis of the employability of workers and the survival/ growth of companies. This specific field of study focuses on the effects of the widespread 
JWL 34,1

implementation of new technologies on the labor market, aiming at evaluating possible consequences of the technological progress on the labor supply and demand, as well as on the workforce composition. The questions that the literature aims to answer are: will the new technologies generate widespread unemployment? Can they lead to the end of human labor? Are economic inequalities set to increase? What effect will the fourth industrial revolution have on the quality of human work that will survive it?

The publications by Brynjolfsson and McAfee "Race against the machine: how the digital revolution is accelerating innovation, driving productivity and irreversibly transforming employment and the economy" (2011) and "The second machine age" (2016), are particularly relevant as they provide valuable insights into the debate on future changes in the labor market. On the one hand, there are those who believe that the risk of computerization is overestimated (Berg et al., 2018; Arntz et al., 2017; David, 2015); on the other hand, there are those who state it is a realistic view of the decades to come and of the challenges we will experience (Caravella and Menghini, 2018; Franzini, 2018; Schwab, 2016; Frey and Osborne, 2013). Many studies show that firms, which invest a lot of money in the development of their employees and in training activities incur big losses due to the lack of transfer of the new competences acquired in the workplace (Caravella and Menghini, 2018; Park, 2017; Makridakis, 2017; Schwab, 2016; Prisecaru, 2016; Frey and Osborne, 2013).

We can highlight two opposite effects on employment described by literature: a disruptive effect, which leads to the replacement of the labor force by obliging workers to unemployment; a capitalization effect which, by increasing demand for new goods and services, leads to the creation of new jobs but also new companies and markets.

Caruso (2017) points out some transversal features that characterize the debate around the future of employment:

- Digitized information has become the strategic resource par excellence and the network plays a crucial role in the organization of the economy and society as a whole;

- The digital economy follows the double principle of increasing returns (because of positive network externalities) and marginal costs very close to zero;

- New business models are emerging which, through collaboration and sharing, make it possible to take direct advantage of bilateral markets and the platform-based economy (Schwab, 2016), accompanied by new competitive dynamics, dominated by the "winner takes all";

- Industry 4.0 allows "accelerated" production of customized mass goods because of the global fragmentation of value chains, the networking of production capacities and the overcoming of borders between producers, sellers and consumers on the one hand and between industry and services on the other; and

- The cause-effect link between technological innovation and productivity has not yet been clearly established, as it is conditioned by the effective implementation of technological innovations at the social level and by organizational changes by companies.

From Caruso's study, it emerges that all those transformations often referred to as the "fourth industrial revolution" have not so far satisfied any of the promises/hopes they have raised. Today the organization of work is no longer horizontal if not partially, workers do not seem to have obtained greater decision-making power and autonomy and work has only become more creative for a sub-fraction of highly skilled workers. On the other hand, work has become more precarious, linked to stricter standards and controls and with a significant 
weakening of the distinction between "working time" and "free time." However, technological innovation is not something external to society, which is, on the contrary, its main generator and promoter. Today, due to the countless variables involved and the exponential rate of growth, it is very difficult to accurately predict the effects of the fourth industrial revolution (Morrar et al., 2017). Awareness of the epochal change that we are willing to experience must serve to face its challenges by limiting damage as much as possible and exploiting its potential to the full (Daemmrich, 2017; Makridakis, 2017; Schwab, 2016; Chung and Kim, 2016). The technology that characterizes industry 4.0 can only reach its real potential in combination with social innovation. To seize the vast opportunities offered by the industrial revolution, technical and social innovations must coexist under the same "sustainability" roof (Morrar et al., 2017).

At stake is the focus on the development of transversal competences and the interaction between humans and machines to improve the sustainable dimensions of a production system. It is necessary that the implementation of new technologies is primarily oriented toward social and environmental sustainability (Morrar et al., 2017; Butera, 2017; Peters, 2017; Pak, 2017; Prisecaru, 2016; Romero et al., 2016) and not to the economic interests of a few, who would lead to an increase in inequalities and/or further environmental damage. Linking new technologies and sustainability entails a relevant investment in organizational learning, seeking to shape the socio-material conditions suitable for such a key issue.

\subsection{New competences to dwell within the digital revolution}

In their study "Holistic approach for human resource management in industry 4.0" Hecklau et al. (2016), describe the possible "core" skills of industry 4.0 starting from the challenges that the latter is called to face. The authors point out different challenges by grouping them into five macro-categories and then deriving the necessary skills:

- Economic challenges: increasing globalization (intercultural skills, language skills, flexibility over time, networking skills and process understanding), increasing the need for innovation (entrepreneurial thinking, creativity, problem-solving, work under pressure, cutting-edge knowledge, technical skills, research skills and understanding of processes), demand for greater service orientation (conflict resolution, communication skills, knowing how to reach a compromise and networking skills), the need for cooperative and collaborative work (ability to work as a team, communication skills and networking skills);

- Social challenges: demographic and social value change (ability to transfer knowledge, tolerance of ambiguity, flexibility in time and place of work and leadership skills), increased virtual work (flexibility related to time and place of work, technological skills, multimedia skills and understanding of IT security), the complexity of processes (technical skills, understanding of processes, motivation to learn, ambiguity tolerance, decision-making, problem-solving and analytical capabilities);

- Technological challenges: exponential growth of technologies and data utilization (technical capabilities, analytical capabilities, efficiency in working with data, coding capabilities, understanding of IT security and compliance), creating collaborative work on platforms (ability to work in teams, virtual communication skills, media skills, understanding of IT security and ability to be collaborative);

- Environmental challenges: climate change and resource scarcity (sustainable mentality, motivation to protect the environment and creativity to develop new sustainable solutions); and 
JWL 34,1

Based on the above clustering, the authors develop a model of skills grouping them into four categories:

- Technical skills: state-of-the-art knowledge, technical skills, process understanding, media skills, coding skills and understanding of IT security.

- Methodological skills: creativity, entrepreneurial thinking, problem-solving, conflict resolution skills, decision-making, analytical skills, research skills and efficiency orientation.

- Social skills: intercultural skills, language skills, communication skills, networking skills, teamwork skills, ability to compromise and cooperate, knowledge transfer skills, leadership skills.

- Personal skills: flexibility, ambiguity tolerance, motivation to learn, ability to work under pressure, sustainable mindset and compliance.

Within this framework, learning and growth of competences become two of the crucial and prior issues for enhancing educational policies and reforms such as those relating to the European Reference Framework of Key Competences for Lifelong Learning, (https://ec. europa.eu/education/education-in-the-eu/council-recommendation-on-key-competencesfor-lifelong-learning_en), which defines the competences of each European citizen needs to achieve personal fulfillment and development, employment, social inclusion and active citizenship. The lifelong learning perspective entails not only political initiatives at the macro level but also strategies and interventions to guarantee that individuals may access economic opportunities, being competitive in the new world of work, shifting the attention at both meso- and micro-level implications for their fulfillment. Global workforce needs to change its professional path because of the changes that digitalization, automation and artificial intelligence progress are bringing to the world of work. The type of skills required by companies has changed, with profound implications for the career paths that individuals will have to pursue. Therefore, it is spreading the need to develop processes of learning new skills (reskilling), so that you can do a different job or train people to do a job differently. The new scenario that emerges on the horizon is changing the contribution and the ways of creating value that human work will provide to organizations and the impact on workers is greater than ever before.

To sum up, the macro lens related to the three main analyzed topics, we can highlight as a transversal feature: the relevance of learning processes to cope with talented resources, the innovative approaches to managerial and organizational dimensions, the new competences and capabilities, the emerging digital challenges delivered by the fourth industrial revolution.

Hence, the need to acquire skills to dwell in a hybrid world, characterized as a knowledge-intensive society, linking new technological opportunities with a multifaceted concern for sustainability.

It becomes, therefore, evident how training and learning to develop innovative competences represent an essential response to the growing challenges impacting contemporary organizations, seizing the opportunities generated by technological 
innovation. In the next chapter, we address the organizational learning processes oriented to the achievement of new competences and work cultures.

\section{Organizational learning for new competences: a meso level viewpoint}

To face constantly transforming operative environments, a new approach is required in conceiving organizations, management and change, enhancing active learning paths and trajectories, as well as seeking higher levels of adaptive knowledge transfer.

Billett $(2000,2001,2004,2020)$ claims for making effective learning environments out of workplaces, developing guidelines for the acquisition of vocational knowledge through participation in everyday work activities.

Gherardi (2009a) argues that organizational practices have become the loci of knowing, organizing and learning, due to the practice turning point in studies on learning and knowing in organizations (Schatzki et al., 2001). The adoption of a practice lens (Gherardi, 2009b) entails a critical epistemological stance that pertains to an innovative cultural climate, encompassing a vast array of contributions on multiple issues such as activity system, a community of practice, knowledge, learning, situated practice, use of technologies (Engeström,1987; Brown and Duguid, 1991; Lave and Wenger, 1991; Blackler, 1995; Easterby-Smith et al., 1998; Clegg and Hardy, 1996; Suchman, 1987; Cook and Brown, 1999; Ciborra, 2006; Orlikowski, 2000, 2002, 2007).

In such a perspective of "practice as the site of learning" (Nicolini, 2011, 2013), organizational learning is conceived as an unfolding social process of becoming a competent member of a workgroup or community (Wenger, 1998), acknowledging, negotiating and adopting rules, roles, languages, division of labor, tools, use of artifacts in a specific workplace context. Knowledge is conceived as socially shaped, collectively shared, distributed and circulating through socio-material dimensions (conversations, discourses, practices, doing), dealing with multiple ways of working, knowing, innovating and organizing: a texture (Gherardi, 2006) of material and immaterial aspects, through which practitioners shape and reshape their system of activity every day, consolidating but also changing their practice and objects, facing internal and external pressures.

The transformation of work as an impact of the 4.0 industrial revolution, accelerated by the pandemic scenario, triggers and challenges organizations to learn with and from their members, developing a highly reactive culture to internal and external stimuli and recreating a suitable climate for the diffusion of knowledge. What is asked is the dare to leap a strict hierarchical structure of teaching and control (often seen and pursued as a managerial reassuring comfort zone), spreading the circulation of knowledge, and therefore the organizational learning. Inside what is known as the knowledge-intensive firm, it is important to grant more responsibility and autonomy to workers to generate continual learning and organizational improvement. Indeed, to unlock the potential of industry 4.0, organizations need to enhance their culture, integrated activities and structure (Lu, 2017; Romero et al., 2016), dealing with organizational learning processes oriented to the achievement of new competences and work cultures.

As historical theoretical models highlighted (Lawrence and Lorsch, 1986; Hambrick, 1983; Lawrence and Dyer, 1983; Thompson, 1967; Barnard, 1938), in such a challenging context the organizations must survive and grow in the long term. To achieve this objective, contemporary organizations ask their employees to work in a more flexible and fast way, also due to the technological progress impacting on the complexity and dynamicity of their working activity (Lu, 2017; Romero et al., 2016; Salas and Cannon-Bowers, 2001; Ford and Fisher, 1996). 
JWL 34,1

Learning, both individually and collectively, is, therefore, one of the most important leverages that organizations must use to obtain important competitive advantages. For an organization, it is essential to learn internally, by means of optimal management of the knowledge possessed by individuals or other resources, as well as from the external environment. Today, more than ever, it is strategic for an enterprise to adopt an effective culture of learning, facing the constant changes happening in social and business contexts, even anticipating them if possible: the issue of nurturing processes of organizational learning entails both initiatives of formal and institutional training and the valorization of available knowledge, embedded in innovative practices and developed day by day through the circulation, consolidation and change of habits, routines, new ways of coping with the internal and external solicitations. Communicating the crucial role of learning to their employees is essential for organizations, implementing adequate training activities to empower and guide its workforce toward objectives of competence development and transfer.

During the past decades, in the effort of providing the employees with the necessary knowledge and competences to face the modern context characterized by self-directed dynamic performances, it has become increasingly common to delegate responsibilities and decisions related to learning (Warr and Bunce, 1995). Organizational learning becomes a learner-centered approach (Bell et al., 2017; American Society for Training Development, 2015), with a growing interest in active learning, whose aim is to transfer competences by means of experience instead of learning a set of top-down taught information (Brown and Duguid, 1991). Hence, an emphasis on the potential of technology-based training, informal learning and community of practice for developing knowledge and skills of the employees.

Hardy et al. (2019) claim for managing exploration (knowledge expansion and innovation) - exploitation (knowledge refinement) trade-offs as a crucial point in modern, learner-centric, dynamic learning and development contexts.

The higher the information-knowledge gap, related to what learners want or need to know/be able to do (e.g. due to technological innovation pressure), the greater the attention that will be addressed to the explorative path of new knowledge; the lower the informationknowledge gap, the greater the investment that will be made to develop, consolidate and disseminate existing and already in use knowledge and competences.

Achieving a good balance between learning efforts for enhancing the use of the available knowledge (exploitation) and the investment in generating innovative knowledge (exploration), facing the uncertainty the organizations must cope with, is strongly related to organizational climate and cultural support to a proper and suitable learning environment.

In this sense, furthermore, the new technologies can become, if adequately implemented, an important tool for the active participation of learners in learning activities. The technological potential for learning has to be explored and taken into consideration seeking to activate organizational learning processes (Sitzmann and Weinhardt, 2018).

In general, strategies that involve participants in a combination of exploration and exploitation lead to effective learning, while strategies that lack this type of involvement or excessively emphasize one activity over the other, are less effective.

All that said, organizational learning cannot be considered the sum of learning experiences of all workforce members; the challenge for dwelling in a competitive and evolving global context is to adopt a reactive and innovative culture, promoting effective paths for the shaping and sharing of knowledge.

Recruiting and gathering talented and competent individuals is not enough, neither it is just encouraging interaction. 
Coping with the spreading digital age, dealing with "digital employees," "digital work" and "digital employee management" (Strohmeier and Parry, 2014), requires relevant shifting points in innovative workplaces:

- a strong revision of the traditional approach in conceiving the managerial function and in achieving new competences and tools for changing and aligning strategies and activities to these new labor features (Fregnan et al., 2020);

- to identify and develop the skills necessary for the workforce of the future, as one of the greatest challenges for organizations in this transition phase;

- a strong and diffused learning culture that allows constant updating of the skills of the employees, with specific regard to the impact of the fourth industrial revolution on workers' activities;

- exploring new learning opportunities and tools; and

- developing the so-called "soft skills," as peculiarly human abilities, which represent the great qualitative difference between man and machine, enhancing a sustainable hybrid production system.

As a consequence of the macro-level solicitations, at the meso level new organizational, professional and work cultures are the key object to be shaped, nurtured, developed and shared, dealing with disruptive changes, transforming them into opportunities for growth and positive evolution (Brown and Duguid, 1991). The relevance attributed to situated, embedded and circulating knowledge, related to the way practitioners conceive and use new technologies (Orlikowski, 2000), conveys the possibility of an organizational learning approach as a suitable and sustainable expansive learning process (Engeström, 2001), going through and beyond resistances, turbulence, criticalities and existing contradictions.

However, the intention to create new knowledge practices and achieve a good balance between digital and physical, constraints and discretion, work and family life, is not straightforward: there is the need to get close to concrete organizational contexts, bridging theory and practice and seeking to understand how the reception of the 4.0 industrial revolution implications is rooted in practice. In the next paragraph, we address a micro-level analysis of how a high-tech company is tackling the problem to prompt new competences through organizational learning leverage.

\section{The Comau HUMANufacturing: a micro-level analysis}

The impact of the fourth industrial revolution on organizations and social systems, on the labor market and on workers' skills, highlights the importance of facing the continuous changes enabled by new technologies. Research and studies point out the connection between effective learning cultures (Plummans et al., 2017; Choi and Jacobs, 2011; Yoon et al., 2010), knowledge management and dissemination (Davenport, 2015), as well as an active approach to training paths (Bell and Kozlowski, 2008; Sitzmann and Weinhardt, 2018).

Hence, the opportunity to explore a concrete organizational context for deepening the tensions between opportunities and risks, willingness to learn and fear of technologies unemployment, new connections between subjects and work, with the purpose to enhance our understanding of the relationship between human beings and machines based on nowadays technologies.

The choice of assuming a pivotal case, albeit not exclusive, to explore approaches, practices, skills and strategies, allows to point out how a company concretely embraces the potential of the fourth industrial revolution, also highlighting criticalities and problems of such a change. Studying the situational uniqueness of a specific context may provide 
JWL 34,1

analytical refinement of what is currently known, addressing the epistemic significance of the particular (Tsoukas, 1989, 2009) and enhancing the possibility to enrich the general concepts related to the issue at hand (Scaratti and Ivaldi, 2021).

The research project has been conducted within Comau, an important Italian multinational company integrated with 20 subsidiaries, based in Turin and part of the FCA Group. Comau develops and implements automation processes, solutions, production services and it is specialized in welding robots. The company is working in 32 locations around the world, divided into 4 main geographic regions: North America, South America, Asia and Europe. Crossed to these regions there are three main business units: robotics, which deals with the design and production of robots traditionally for industrial use; the automation system, which deals with the design of the production lines within which robots are typically inserted; and the powertrain, which is the unit dedicated to the production of machine tools.

Comau is made up of 12,600 employees and has started important international training collaborations (10 international training partners). All the company's activities are strictly connected to innovation.

Because of the combination of advanced technological know-how and its long-term experience, the organization is stimulated to undertake a process of constant innovation that gives life to new products, advanced technologies and an innovative factory concept that optimizes the automation oriented to man and machine.

The company's vision, facing the challenges of a constantly evolving market, is summarized by the concept of HUMANufacturing, like a weave between the fourth industrial revolution and the possibility to place humans at the center, as well as to remark the role of technology as a useful tool to help satisfy human needs. Comau is in fact committed to implementing technology-enabled solutions for Industry 4.0 such as innovative real-time data transfer techniques, virtual reality and the latest generation of wearable devices.

The company presents suitable features to be studied as an emblematic case:

- being engaged in continuous research and open innovation, today Comau seeks to integrate the 4.0 paradigm into its organizational culture;

- learning has a central role within the company, as the numerous international training partnerships demonstrate;

- the company faces an important global presence that allows being highly reactive to the different environments in which it is inserted;

- the corporate vision aims to develop the human-machine relationship as a core value of the HUMANufacturing approach (declined in the adoption of Cobots and exoskeletons); and

- finally, the company commitment is strongly oriented to promote knowledge transfer, transmitting the 4.0 culture to new generations.

Two were the principal aims in studying the Comau case: the first refers to the actual experience of the organizational members facing the changes and the challenges they have to cope with; the second is related to the company approach seeking to promote organizational learning.

Therefore, we sought to point out:

- The professional history of employees, their interpretation of their role in the company and the changes observed in their working activities; 
- The new approaches to work, the role of technology and the main technologies adopted today within the company;

- The fundamental skills within the company;

- The role of learning, as well as the knowledge diffusion and management to face the stimuli and continuous changes in the operating environment; and

- The organizational culture and the changes needed to effectively exploit the potential of the fourth industrial revolution.

Dealing with the actual experience and facing the meaning people give to their personal and professional trajectory, we adopted a qualitative methodological approach, following the "grounded theory" guidelines (Glaser and Strauss, 1967; Charmaz and Belgrave, 2007). The research was carried out through six semi-structured individual interviews and two focus groups, involving company employees. The interviewees were identified on the basis of the availability of respondents, among a sample proposed by the human resource (HR) management function on the basis of their key role within the business change process (agents of change) and the time spent working for the company (changes observation); the focus groups' participants were invited asking to confirm via e-mail their availability, on the basis of their participation to the company specializing master, their young age (Generation $\mathrm{Y}$ ) and their recent entry into the company. Each participant received an informative sheet concerning the respect of both their privacy and anonymity.

The intention was to detect knowledge about the organizational learning process both from senior staff, involving internal managers as carriers of project purposes and from the target of the learning process, considering their interpretation of the learning path experienced to achieve new competences. Dealing with the former, we gathered knowledge about the learning projects at stake, while the latter pointed out their involvement in a two-year executive master (with a pause of one week per month). The first year of the masters was related to academic disciplinary fields, the second one was focused on a learning path immersion within the Comau organization, acknowledging the emerging innovative culture through situated project works with other employees.

For both the interviews and the focus group activities, being semi-structured, it was provided a draft containing the general questions to be asked to the interlocutors, assuming a conversational orientation giving space to unfolding, discourse, comments, considerations. The draft was mainly used to identify the topics considered essential for the purposes of the research.

Draft of individual interview:

- Can you tell me who are you? What is your role within Comau? (when you arrived, why, with what objectives). If you have been working as a manager or you have been with Comau for a few years, have you been able to observe changes in your job or role?

- Nowadays we talk about the fourth industrial revolution, in your opinion, what are the most significant changes it is generating in the world of work?

- Thinking about the Comau context, what are the knowledge, skills and activities most requested to workers?

- How could organizations help workers to be prepared for today's world of work? What does Comau do in this sense? 
JWL 34,1

For the HR managers:

- What does it mean to be a worker today? What do you think they need most? What are the required skills and knowledge and how should learning paths be structured? According to which drivers?

For digital team managers:

- What is the role of technology today? How is technology changing the way people relate to work?

Draft of the focus group:

- $1^{\text {st }}$ Step: Presentation

- Round table presentation of the participants in the focus group (who they are, how long they have been with Comau, what role they play).

- $2^{\text {nd }}$ Step: Investigation of the changes of the fourth industrial revolution

- Nowadays we talk about the fourth industrial revolution, what are the most significant changes it is generating in the world of work?

- What does it mean to you being a manager today? What differences do you find, if compared to the past?

- What do you think are the most important knowledge and skills for workers and managers today?

- What should an organization do to encourage learning and promotion of the culture of the fourth industrial revolution? What role should managers play?

- $\quad 3^{\text {rd }}$ Step: Focus on the specializing master experience

- What adjectives/words would you use to describe the specializing master experience?

- What are the drivers that were transmitted to you within the specializing master organized by the Comau Academy?

- What were the situations of the specializing master that most favored your learning?

- If we were to do a Comau SWOT analysis about the promotion of learning, what do you think are its strengths, weaknesses, constraints and opportunities?

The following six employees were interviewed: A- head of HR recruiting and of the "digital initiatives platform" cross-sector entity (20 years within the group); B- digital team manager (33 years within the group); C- digital team manager and head of funded projects (22 years within the group); D- innovation manager (7 years within the group); E- training and e-service manager (18 years within the group); F- business development manager at the corporate level and in the robotics business unit (30 years within the group). 
For the focus groups, 16 people were randomly invited among the participants at the specializing master, focusing on their belonging to the generation Y (born between 1980 and 1999) and seeking to explore their learning experience as young workers who have joined the company a little time before.

Having recently participated in a learning path and having recently joined the company (as well as the world of work), their contribution could have been particularly useful in understanding the learning needs perceived by workers and the alignment of the activities offered by the company to the needs of its own employees. The focus groups were, therefore, essential to understanding how workers were involved in the company and to discuss their expectations with them.

\subsection{Findings}

The interviews and group discussions have been audio-recorded, transcribed and carefully analyzed, adopting both a phenomenological and semiotic perspective (Mininni and Manuti, 2017), as well as a ricoeurian hermeneutic orientation (Bartunek and Louis, 1996; Cunliffe and Locke, 2019).

The analysis of the data permitted to highlight some important dimensions connected to the promotion of organizational learning inside 4.0 industry:

- the enhancement of new approaches to work (related to the points of interest I and II);

- the introduction of new competences (related to the point of interest III); and

- the promotion of a cultural change (related to the points of interest IV and V).

What emerges from the analysis of the results as a transversal issue is that technology is accelerating and simplifying operations that once were difficult and required a lot of time and resources. Even in the automotive sector, the software is now a primary component and, for a company traditionally working with physical materials, this kind of change underlines the necessity of reviewing the organizational processes.

- Regarding the new approaches to work, the most important required change refers to the shifting from a logic of execution to a logic of improvement of the working processes.

Comau is now organizing teams and activities into projects, instead of following a functional structure:

"There are two types of changes: changes of a technical nature and changes of a cultural, managerial or rather general type. From a technical point of view, all our products must be equipped with options that allow data reading or remote management. From a purely cultural and social point of view, new professions are certainly being created and others are probably disappearing" (D1).

"We are moving from a product culture to a service culture. This is a big change and not only at an industrial level. The machines that are rented today in the cities constitute the acquisition of a service and not a product. A similar thing is happening also for the machine tools" (F1).

This business activities organization simplifies the sharing of competences and influences the approach to career. The choices linked to the professional career of workers are increasingly self-directed, instead of depending on a dedicated institution:

"This clearly has an impact on people's careers too, how they see their work, etc. [. . .] it's all very different and seen from the outside it can seem very confusing, but seen from the inside it doesn't. 
JWL 34,1

The effort is not to design an organization, but it is always to be clear in what you do and what you don't do. Because again, you don't have a job description, you rather have a skills profile that you make available to what there is to do and what you like to do" (A1).

"The approach to career is also different because there is no longer a staff body that, together with your boss, designs your path; of course, they do it, but on macro trends. What you will do the next day must also be manifested by yourself and this is a big change" (Focus group, I, 1).

A second feature emerging from the interviews is that workers choose whether to participate in a project because of their competencies and their will to do it. The result is a "nebula organization" that seen from the outside can seem pretty much confused, but internally is well organized because everybody knows who the supervisor is:

"Shaping a very fluid work organization with clear objectives is in fact something that never ends. One piece of the project ends, but another one opens up and you have to start all over again, re-explain it, communicate it again within the teams, outside the teams and within the organization. It is always in the process of becoming [ . . ] more than a hierarchical organization, it is a nebulous interlocking organization" (E1).

"Assigning activities to a person is based on the skills he/she possesses and what he/she desires. It's a very different thing from the classic way of working, where a person has a role and has a job description and does that until they change his/her role if they change it. These teams are extremely permeable teams. The teams are organized and everyone knows who his/her boss is, but someone who writes software can also work on the commercial proposal to the client because he/she has the skills to do it and wants to do it. He/she can, thus, contribute with his/her own skills and get help for those he/she does not have" (C1).

"I have been here for two years and in this period of time, my work has changed a lot. We observe many changes at the level of technical solutions that are adopted to design a line from scratch. An example is AGVs, which are a technology that was inconceivable to install on lines up to 10 years ago. Today the idea of no longer having lines that are real straight lines, but that is much more flexible, certainly facilitates our work in many situations, allowing much more flexibility to solutions" (Focus group, I, 2).

A third aspect is that collaboration between humans and machines is becoming essential for companies. It is important to underline that machines are becoming intuitive to use because they are designed to communicate like humans; differently from the past, when humans had to adapt to machines (acquiring specific skills and knowledge) to use certain tools. The adopted direction, as the founding assumption of the HUMANufacturing culture, is the ennobling of human work and the removal from repetitive and alienating activities. Workers are now paid to improve processes and not just to execute them:

"Technology must be functional to our needs as human beings. It will not replace us because there are things that cannot be replaced and, above all, we do not want it to happen” (B1).

"Moving a small bottle of water is not a human competence. Understanding where it is best to move it, that is a human skill. It has been occurring a big change in the interpretation and approach to work: from the execution of processes to the improvement of processes" (B2).

"I believe that the technology that most affects human work within the 4.0 paradigm is represented by collaborative robots. I believe they can make a difference. Staying on the 'site' I've 
seen how they affect various aspects of human activity such as safety in work environments characterized by the presence of Robots" (Focus group, II, 4).

The transformation of the working approach is not taken for granted and also entails problems and difficulties to be handled:

"The inclusion of suppliers relationship management was disruptive from all points of view [...] Let's say that the way of working has changed and had to lead to a speeding up of all processes and greater flexibility of individuals, but it requires effort because it takes time and people need to understand the potential to lighten the work that comes with it [...]" (F 2).

"In general, it is increasingly difficult to separate personal life from what is working life. This is because we are increasingly connected [. . . Unfortunately, I read e-mails at all hours. It is always going more and more toward this direction" (Focus group, II, 3).

- About the introduction of new skills and competencies, the participants state that technical skills remain essential in the industrial sector but even out of it if we think about the pervasiveness of technology in today's human experience. Such skills are useful to use certain tools and to understand their potential:

"In the world of work, industry 4.0 gave me work, in the sense that I am a 'data scientist' and this figure was born and raised because of industry 4.0. It is becoming a widespread figure even if we will discover its actual usefulness just in a while" (Focus group, II, 5).

"In the plants, we begin to see the first workers who work wearing a watch and no longer using tools such as sheets of paper. Today these figures use tablets, smartphones, watches and soon will use the voice. Let's say that there is a progressive change even for these professional figures because of the use of increasingly sophisticated technologies and related competences" (F3).

In addition, many participants highlighted the necessity of figures with transversal skills and broad horizontal culture, allowing them to have an overview of the different activities:

"The real novelty is precisely the introduction of people who are able to extract value from the data collected and people who are able to get the data to these systems by understanding what type of sensors to use and where to put them" (Focus group, I,6).

"The ability to collaborate or team working is fundamental. More and more there are very different skills that acquire importance [...] it becomes more and more difficult for a person to have the necessary knowledge to complete a job [... ]" (A2).

"It is clear that soft skills such as problem-solving, project management, teamwork and flexibility are all strictly necessary. Especially if you get to cover managerial roles and enter middle management. An individual who does not know how to work in a group would not know how to work in a company that sees groups interconnected according to a logic of platform, in which they all work together to achieve the same goal. The other project management skills are equally fundamental. Today almost all activities are organized by projects, so knowing how to work and organize oneself by projects, finishing activity calendars, finishing the progress of the work control etc. [...]" (Focus group, I, 5).

Finally, soft skills are increasingly important for companies. For example, the dynamicity of operative environments and the high level of specialization of workers underline the importance of flexibility and ability to collaborate, as in the following quote: 
JWL 34,1

\section{8}

"[...] the reason why Comau hired us is precisely that of contaminating with our flexibility the others who have instead the technical skills deriving from a more consolidated experience. We had to transfer our 'less technical' skills, to put it in simplistic terms, to those who have been here for several years, exploiting our adaptability and flexibility" (Focus Group, II, 7).

The achievement of new competences is not straightforward either and some criticalities emerge:

"At the moment in Comau, there are different approaches between people: those who manage the traditional business in a more traditional way and those who manage the most innovative business in a more innovative way. Innovative means a lot of things. First, knowing how to use tools that did not exist until 10 years ago. I refer in particular to working on a digital platform or working on Google platforms, where everything is shared and there is nothing local [...] you need to know how to work beyond space" (C2).

"There is not a method to validate the software yet. At the management level, there is still no preparation for software development because there are methods/standards that are used within software engineering but here they have not been implemented yet” (F3).

"[...] a discourse of risks exists [...] We may be facing critical issues and problems never faced before and given that, the experience significantly affects our work, change can be seen as too high a risk" (Focus group, I, 7).

"Access to new skills can be seen as a limit by those who have been in this job for a long time or who have created their own comfort zone and do not want to leave it. I don't think it's a limit for us, on the contrary, I think it's an opportunity" (Focus group, I, 4).

"There is not enough communication, and therefore the competences related to the fourth industrial revolution are not shared between the different business units" (E2).

- The third dimension is related to the promotion of cultural change. Comau, besides the learning activities, is adopting techniques such as job rotation and the creation of inter-generational and inter-functional teams. Such paths can help workers to gain an overview of the different activities and ease the coexistence of different approaches within the organization. Moreover, the company is creating diffuse connections among people, to boost the internal diffusion of knowledge and with external realities through partnerships, to seek the competencies not yet achieved.

To change the processes can be hard work and can take months, but to change the culture of a company is even a bigger challenge because it is strictly rooted within the company history, values and activities, as well as within its members' background:

"Certainly, it is not an easy thing since you have to clash with practices that have always existed. However, Comau is entering industry 4.0 and is changing the processes, and therefore the heart and the engine of the company. For the automation system, over the last year, the processes have been retouched and revised from all points of view. Our organization is changing and has changed a few months ago according to this new vision that the company has acquired" (B3).

"It is difficult to interpret what a customer wants because it is a myth that the customer knows what he wants. There are latent needs that not even market analysis is able to capture and that you have to be good at interpreting. There is a world that is so dynamic and liquid that it is difficult to understand it. I don't think there is resistance, but I believe that being confused by a thousand things, we find it hard to find the right path" (Focus group, II. 8). 
"Some drivers can be seen as the backbone of our change. The first is open-mindedness, and therefore the ability to look beyond one's habits and patterns. The second is accountability, that is, taking risks at all levels of the organization because when certainties fail, you need to know how to interpret new environments. A third could be the opening of vision, in the sense that now even a classic industrial company like ours can no longer avoid looking systematically outside of itself. Because resources and skills are shared. You can no longer think about drawing your own path without systematically look around. The last driver I would like to point out is the customer, both the one who buys and the internal one. You are much more than before compared to people close to you with expectations, whether they are your employees, bosses or colleagues and who are used to express themselves also due to the fact that we are now connected. In the relationship with the employee, it is now the employee himself who tells me what he needs and what his expectations are. So, hyper-connection is another aspect that you cannot ignore because we are now connected" (E3).

Comau, to deal with this kind of change, instead of imposing it, has chosen an interesting way: the strong involvement of people as first promoters and authors of organizational change:

"[...] to adopt the exoskeleton, Comau selected key operators on the basis of certain features (potential change agents) and proposed them a set of technologies among which they picked the exoskeleton as the best tool to improve their activities. Then these operators participated in the whole design phase till the actual implementation. Their colleagues observing them immediately understood the potential of such technologies and started using them without resistances [...]" (Focus group, I, 5).

"The way in which Comau is spreading this new culture is by involving people and there is no better way. You must involve people so that they begin to use these technologies and methodologies little by little. The same people who begin to use them become agents of changing themselves and begin to contaminate others until a complete diffusion of these new methodologies and technologies" (B4).

"The reason why they hired us and inserted us like crazy cells within the company is precisely to contaminate with our flexibility the others who instead have the skills of those with a more consolidated experience. It's a bit like a virus that starts from a small group of people and then spreads. There is a healthy bacterium that is carried by some healthy carriers until it spreads to all the people within the company" (Focus group, II, 7).

"I take people who are young, not so much from the age point of view, but more from an intellectual point of view and who are, therefore, led to experimenting and I bring them to use new processes and technologies. These, in turn, become agents of change, so that people who are less inclined to accept such changes can see and follow them by imitation" (A3).

"Certainly, with inter-generational teams and inter-functional teams this type of culture can spread and we are observing it. For example, when we work on the proposal phase, we do it in close contact with all the other business units" (B5).

To govern the learning processes aimed at promoting, developing and disseminating the HUMANufacturing culture, Comau has set up an internal academy, with the aim of creating and monitoring multiple training and learning initiatives, in partnership with various international stakeholders.

Seeking to sum up the most relevant results emerging from the qualitative inquiry, we can underline that in Comau the new approach to work is based on specific processes and structures, in which acceleration and simplification, project-based organization (inter-functional 
JWL 34,1

and inter-generational teams), open innovation and tuning on strategic goals coexist, as the metaphor of the nebulous interlocking organization (E1) highlighted. The representation of the fourth industrial revolution and its implications concerns the enabling technologies implementation within industrial environments, based on a cultural transformation. This entails not only the spread of new technologies and machines, rather a rooted in-practice use of innovative technology by the practitioners, acquiring the necessary skills to master and fully understand it (Bondarouk and Brewster, 2016; Ivaldi and Scaratti, 2020).

In relation to the development of new competences, Comau, as the qualitative data point out, emphasizes the relevance of both transversal skills (from execution to entrepreneurship) and digital capabilities (for the interaction between humans and machines). At stake are professional movements from knowledge accumulation to empowerment, toward a more problem-solving orientation and the active participation in practical and sense-making processes.

Concerning the cultural change, Comau promotes a HUMANufacturing approach, in which listening to the practical knowledge, responsibility toward new generations, orientation toward clients and giving value to diversity as a resource constitute the core values of a high-tech company focused on the relevance of organizational members and the sustainable relationship between persons and technology.

Albeit emblematic, the Comau case cannot be mechanically replicated, due to its uniqueness and peculiar specificity compared to other organizational contexts involved in the challenge to cope with the digital revolution. Anyway, it conveys some transversal issues that must be addressed in multiple workplace situations faced with the pressure of technological innovation.

In dealing with this change, a relevant issue to be considered is the necessary work for breaking existent habits and in-use systems of activity, facing and tackling with possible resistances at three levels:

(1) Individual

due to a representation of technology as a threat in relation to low confidence and usefulness, scarce awareness of the added value and implicated meaning connected to work in terms of return of charges instead of advantages. The challenge is the enhancement of active collective participation.

(2) Relational

regarding the diversity of knowledge and digital background among the practitioners and their expectations for upgrading positions related to professional proficiency. The challenge is the creation of good enough conditions for the convergent evolution of different approaches.

(3) Organizational

related to the embedded procedures to be questioned or contested and the fear of mistakes or about tackling with consolidated powers. The challenge is the possibility to achieve a different managerial approach, coping with the unexpected and the complexity of internal and external organizational environments.

Other hints and suggestions can be highlighted from the triggering exploration of the Comau case:

- the importance of a strong alliance between top management and the engagement of key figures (middle managers, young generations) as ambassadors for the creation of a new culture; 
- the promotion of a diffuse awareness concerning the value of adopted technologies, improving participation, the coexistence of different approaches and a diffused mindset of managing the unexpected;

- the involvement of employees at all levels in projects and events that give concrete evidence for the company's interpretation of the fourth industrial revolution, so that they begin to use these new technologies and methodologies little by little, becoming agents of changing themselves;

- the role played by institutional artifacts (in the Comau case, the Academy) and learning processes to spread the new culture; and

- the care of paradigm-shifting, widespread contamination and sharing, creation of accessible memories (report, internal documents [...]).

As a final result, the findings acquired through the study of the Comau case can support and endorse what the scientific literature highlights about the impact, the new competences and the learning paths solicited by the emergence of the fourth industrial revolution: shifting from a logic of execution to a logic of improvement entails a new approach to work, a good enough balance between technical and social competences and the development of innovative work, professional and organizational cultures.

Such a cultural change is not taken for granted and must be accompanied through an organizational learning process, enhancing activities engaged in transformation efforts and promoting multiparty encounters, discussions and debates. This learning process conveys, in turn, the need to cope with tensions and contradictions people face in struggling with persistent problems and challenges in their workplace walk (Ivaldi and Scaratti, 2016, 2020; Scaratti et al., 2017). Assuming that the tension of change and future-orientation also implies material and immaterial dimensions, as people engaged in nowadays organizational contexts are asked to explore processes of learning from the fields, connecting action and thought, as well as trying to open new visions not yet available for transforming and improving their daily practices.

\section{Conclusions}

Aiming to enhance the debate around the fourth industrial revolution, the paper addressed questions related to its relevance and impact, to the implications for organizational learning processes and to the development of new approaches to work, new competences and cultural change.

As highlighted by the literature review, the fourth industrial revolution yields an ambivalence in the introduction of technology, identifying both potentials and risks, respectively, related to the opportunity of social growth on the one hand and of technological unemployment and worse work conditions on the other hand. As sustainability is the key to balancing the strengths and threats of the fourth industrial revolution, that can be achieved if there is a strong investment in the promotion of organizational learning. A learning process in which the experience and practical knowledge of people represent important resources for the introduction, the development and the integration of innovative technologies, matching both knowledge exploration and exploitation.

Managing and engaging people in such a process of expansive learning, as highlighted in the Comau case study, can emblematically express the challenge of the current organizational scenarios characterized by meaninglessness and uncertainty, in which people must deal with contradictions, criticalities and problematic situations. The organizational culture change promoted within Comau's context can be identified as an 
JWL 34,1

agile way of work, that requires: adaptability, maintaining a high level of flexibility and capability to adjust, modify and change a project during its life cycle, going beyond a predictive and waterfall top-down approach; visibility, allowing plural stakeholders to have a view of the multiple aspects involved and to acknowledge the complexity of what is at stake; value generation, since the beginning of the process spreading the concept of value to include not only economic but also eco-friendly, sustainable and ethic dimensions; risks facing, seeking for their reduction and management through a reconfiguration of the relationship connecting scope, time and cost. In a general market and organizational context characterized by a high level of uncertainty, relevant environmental chaos and complexity, an agile approach to work is preferred and recommended, to satisfy the expectations of customers (Sletholt et al., 2011).

The COVID-19 pandemic plays a relevant role in depicting such a scenario, in which practitioners and professional workers are coping with uncertain circumstances and facing contradictions in their daily organizational experience. At the same time, they are asked to make sense out of them, seeking new possibilities of action related to their object-oriented activity. In this perspective, the coronavirus situation can act as a litmus test and a situational organizer for both boosting the introduction and spreading the use of technological devices, as well as for soliciting the cultural change at different levels to cope with severe societal problems.

As shown by the Comau experience and vision, at stake is the need to place humans at the center both as technology recipients and guides toward technological progress. At the organizational level, this means giving back the responsibility of certain tools' choices and their implementation to users. At the social level, this requires the awareness that humans create machines and that they are leading technological progress. Today this awareness is not a foregone conclusion, as the social anxiety about the impact of technologies on the social systems is due to the perception of technology as something external to humans that we can only suffer. To direct the technological progress toward the needs of the community, as the emergence of coronavirus is teaching us, a joint intervention of institutions, the academic world and the industrial world is necessary.

\section{References}

Alvesson, M. and Sandberg, J. (2013), Constructing Research Questions: Doing Interesting Research, Sage, London.

American Society for Training Development (2015), “2015 State of the industry report”, available at: https:/trainingmag.com/trgmag-article/2o15-training-industry-report/

Bakardjieva, M. (2005), Internet Society: The Internet in Everyday Life, Sage, London.

Barnard, C.I. (1938), Functions of the Executive, Harvard University, Cambridge, MA.

Bartunek, J.M. and Louis, M.R. (1996), Insider/Outsider Team Research, SAGE Publications, Thousand Oaks, CA.

Bell, D.S. and Kozlowski, S.W. (2008), "Active learning: effects of core training design elements on selfregulatory processes, learning and adaptability”, Journal of Applied Psychology, Vol. 93 No. 2, pp. 296-307.

Bell, B.S., Tannenbaum, S.I., Ford, J.K., Noe, R.A. and Kraiger, K. (2017), "100 Years of training and development research: What we know and where we should go", Journal of Applied Psychology, Vol. 102 No. 3, pp. 305-323.

Billett, S. (2000), “Guided learning at work”, Journal of Workplace Learning, Vol. 12 No. 7, pp. 272-285. 
Billett, S. (2001), "Learning through work: workplace affordances and individual engagement", Journal of Workplace Learning, Vol. 13 No. 5, pp. 209-214.

Billett, S. (2004), "Learning through work: Workplace participatory practices", Workplace Learning in Context, Routledge, New York, NY, pp. 125-141.

Billett, S. (2020), Learning in the Workplace: Strategies for Effective Practice, Routledge, New York, NY.

Blackler, F. (1995), "Knowledge, knowledge work and organizations: an overview and interpretation", Organization Studies, Vol. 16 No. 6, pp. 1021-1046.

Blinerd, A.S. (2006), "Education for the third industrial evolution", The American Prospect, Vol. 163, pp. 44-46.

Bondarouk, T. and Brewster, C. (2016), "Conceptualizing the future of HRM and technology research", The International Journal of Human Resource Management, Vol. 27 No. 21, pp. 2652-2671.

Brown, J. and Duguid, P. (1991), "Organizational learning and communities of practice: toward a unified view of working, learning and innovation”, Organization Science, Vol. 2 No. 1, pp. 40-57.

Butera, F. (2017), "Lavoro e organizzazione nella quarta rivoluzione industriale: la nuova progettazione socio-tecnica”, L’industria, Vol. 38 No. 3, pp. 291-316.

Caravella, S. and Menghini, M. (2018), "Race against the machine. Gli effetti della quarta rivoluzione industriale sulle professioni e sul mercato del lavoro", L' Industria, Vol. 39 No. 1, pp. 43-68.

Carroll, N. and Conboy, K. (2020), "Normalizing the 'new normal': changing tech-driven work practices under pandemic time pressure", International Journal of Information Management, Vol. 55, pp. 102186.

Caruso, L. (2017), "Digital innovation and the fourth industrial revolution: epochal social changes?", $A I$ and Society, Vol. 33 No. 3, pp. 379-392.

Castells, M. (1996), The Rise of Network Society, Blackwell, Malden, MA.

Charmaz, K. and Belgrave, L.L. (2007), Grounded Theory. The Blackwell Encyclopedia of Sociology, Blackwell Publishing.

Choi, W. and Jacobs, R.L. (2011), "Influences on formal learning, personal learning orientation and supportive learning environment on informal learning", Human Resource Development Quarterly, Vol. 22 No. 3, pp. 239-257.

Chung, M. and Kim, J. (2016), "The internet information and technology research directions based on the fourth industrial revolution", KSII Transactions on Internet and Information Systems, Vol. 10 No. 3, pp. 1311-1320.

Ciborra, C. (2006), "The mind or the heart? It depends on (the definition of) situation", Journal of Information Technology, Vol. 21 No. 3, pp. 129-139.

Clegg, S. and Hardy, C. (1996), "Organizations, organization and organizing", in Clegg, S., Hardy, C. and Nord, W. (Eds), Handbook of Organization Studies, Sage, London, pp. 1-28.

Cook, S.D.N. and Brown, J.S. (1999), "Bridging epistemologies: the generative dance between organizational knowledge and organizational knowing", Organization Science, Vol. 10 No. 4, pp. 381-400.

Corazza, L. (2017), "Industria 4.0: lavoro e non lavoro di fronte alla quarta rivoluzione industriale", Economia and Lavoro: rivista Quadrimestrale di Politica Economica, Sociologia e Relazioni Industriali, Vol. 52 No. 2, pp. 15-22.

Cunliffe, A. and Locke, K. (2019), "Working with differences in everyday interactions through anticipational fluidity: a hermeneutic perspective", Organization Studies, Vol. 41 No. 8, pp. 1079-1099.

Daemmrich, A. (2017), "Invention, innovation systems and the fourth industrial revolution”, Technology and Innovation, Vol. 18 No. 4, pp. 257-265.

Easterby-Smith, M., Snell, R. and Gherardi, S. (1998), "Organizational learning and learning organization: diverging communities of practice?”, Management Learning, Vol. 3, pp. 259-272. 
Engeström, Y. (1987), Learning by Expanding: An Activity Theoretical Approach to Developmental Research, Orienta Konsultit, Helsinki.

Engeström, Y. (2001), "Expansive learning at work: toward an activity theoretical reconceptualization”, Journal of Education and Work, Vol. 14 No. 1, pp. 133-156.

Ford, J.K. and Fisher, S. (1996), "The role of training in a changing workplace and workforce", New Perspective and Approaches, Blackwell Publishing, Cambridge, MA.

Franzini, M. (2018), "Intelligenza artificiale e prospettive del lavoro: il ruolo delle istituzioni economiche", Giornale Italiano di Psicologia, Vol. 45 No. 1, pp. 125-130.

Fregnan, E., Ivaldi, S. and Scaratti, G. (2020), "HRM 4.0 and new managerial competence profile: the COMAU case", Front. Psychol, Vol. 11, p. 578251, doi: 10.3389/fpsyg.2020.578251.

Frey, C.A. and Osborne, M.A. (2013), The Future of Employment: How Susceptible Are Jobs to Computerization?, Oxford Martin School, University of Oxford.

Garrett, B. (2013), An Emerging Third Industrial Revolution, Atlantic Council, December 4.

Gherardi, S. (2006), Organizational Knowledge: The Texture of Organizing, Blackwell, London.

Gherardi, S. (2009a), "Knowing and learning in practice-based studies: an introduction”, The Learning Organization, Vol. 16 No. 5, pp. 352-359.

Gherardi, S. (2009b), "Introduction: the critical power of the 'practice lens", Management Learning, Vol. 40 No. 2, pp. 115-128.

Glaser, B. and Strauss, A. (1967), The Discovery of Grounded Theory, Weidenfield and Nicolson, London.

Hambrick, D.C. (1983), "Some tests of the effectiveness and functional attributes of miles and snow's strategic types", Academy of Management Journal, Vol. 26 No. 1, pp. 5-26.

Hardy, J.H., Day, E.A. and Arthur, W. Jr (2019), "Exploration-exploitation tradeoffs and information-knowledge gaps in self-regulated learning: Implications for learner-controlled training and development”, Human Resource Management Review, Vol. 29 No. 2, pp. 196-217.

Hecklau, F., Galeitzke, M., Flachs, S. and Holger, K. (2016), "Holistic approach for human resource management in industry 4.0", Procedia CIRP, Vol. 54, pp. 1-6.

Ivaldi, S. and Scaratti, G. (2016), "The formation of germ cell for organizational learning", Journal of Workplace Learning, Vol. 28 No. 4, pp. 224-244.

Ivaldi, S. and Scaratti, G. (2020), "Narrative and conversational manifestation of contradictions: social production of knowledge for expansive learning", Journal of Learning Culture and Social Interaction, Vol. 25, pp. 1-13.

Janssens, M. and Steyaert, C. (2009), "HRM and performance: a plea for reflexivity in HRM studies", Journal of Management Studies, Vol. 46 No. 1, pp. 143-155.

Jones, S. (1998), Cybersociety 2.0: Revisiting Computer-Mediated Community and Technology, Vol. 2, Sage, London.

Lave, J. and Wenger, E. (1991), "Situated learning”, Legitimate Peripheral Participation, Cambridge University Press, Cambridge.

Lawrence, P.R. and Dyer, D. (1983), Renewing American Industry, Free Press, New York, NY.

Lawrence, P.R. and Lorsch, J.W. (1986), Organization and Environment: managing Differentiation and Integration, Harvard Business School Classics, Harvard.

Lu, Y. (2017), "Industry 4.0: a survey on technologies, applications and open research issues", Journal of Industrial Information Integration, Vol. 6, pp. 1-10.

MacCarthy, M. (2014), “Time to kill the tech job-killing myth, the hill”, available at: http://thehill.com/ blogs/congress-blog/technology/219224-time-to-kill-the-tech-job-killing-myth

Makridakis, S. (2017), "The forthcoming artificial intelligence (AI) revolution: Its impact on society and firms", Futures, Vol. 90, pp. 46-60. 
Mininni, G., Manuti, A. (2017), "A rose is more than a rose. . . the diatextual constitution of subjects and objects”, Text Talk, Vol. 37, pp. 243-263.

Morrar, R., Arman, H. and Mousa, S. (2017), "The fourth industrial revolution (industry 4.0): a social innovation perspective", Technology Innovation Management Review, Vol. 7 No. 11, pp. $12-20$.

Nicolini, D. (2011), "Practice as the site of knowing: Insights from the field of telemedicine", Organization Science, Vol. 22 No. 3, pp. 602-620.

Nicolini, D. (2013), Practice Theory, Work, and Organization. An Introduction, Oxford University Press, Oxford.

Orlikowski, W. (2000), "Using technology and constituting structures: a practice lens for studying technology in organizations", Organization Science, Vol. 11 No. 4, pp. 404-428.

Orlikowski, W.J. (2002), "Knowing in practice: enacting a collective capability in distributed organizing", Organization Science, Vol. 13 No. 3, pp. 249-273.

Orlikowski, W.J. (2007), "Sociomaterial practices: exploring technology at work", Organization Studies, Vol. 28 No. 9, pp. 1435-1448.

Park, S.C. (2017), "The fourth industrial revolution and implications for innovative cluster policies", $A I$ and Society, Vol. 33 No. 3, pp. 433-445.

Peters, M.A. (2017), “Technological unemployment: Educating for the fourth industrial revolution”, Educational Philosophy and Theory, Vol. 49 No. 1, pp. 1-6.

Plummans, L., Printz, S., Vossen, R. and Jeschke, S. (2017), "Strategic management of personnel development in the industry 4.0", International Conference on Intellectual Capital and Knowledge Management and Organizational Learning, Academic Conferences International Limited, pp. 179-186.

Prisecaru, P. (2016), "Challenges of the fourth industrial revolution”, Knowledge Horizons- Economics, Vol. 8 No. 1, pp. 57-62.

Rifkin, J. (2016), "The 2016 world economic forum misfires with its fourth industrial revolution theme", The economist, Jan. 15, 2016.

Romero, D., Stahre, J., Wuest, T., Noran, O., Bernus, P., Fast-Berglund, Å. and Gorecky, D. (2016), “Towards an operator 4.0 typology: a human-centric perspective on the fourth industrial revolution technologies", In International Conference on Computers and Industrial Engineering (CIE46), pp. 1-11.

Salas, E. and Cannon-Bowers, J.A. (2001), "The science of training: a decade of progress", Annual Review of Psychology, Vol. 52 No. 1, pp. 471-499.

Scaratti, G. and Ivaldi, S. (2021), "Uniqueness and generalization in organizational psychology: Research as a relational practice", Frontiers of Psychology, Vol. 12, p. 638240, doi: 10.3389/ fpsyg.2021.638240.

Scaratti, G., Ivaldi, S. and Frassy, J. (2017), "Networking and knotworking practices: work integration as situated social process", Journal of Workplace Learning, Vol. 29 No. 1, pp. 2-23.

Schatzki, T.R., Knorr-Cetina, K.D. and Von Savigny, E. (2001), The Practice Turn in Contemporary Theory, Routledge, London.

Schwab, K. (2016), The Fourth Industrial Revolution, Crown Business, London.

Sitzmann, T. and Weinhardt, J.M. (2018), "Training engagement theory: a multilevel perspective on the effectiveness of work-related trainin", Journal of Management, Vol. 44 No. 2, pp. 732-756.

Sletholt, M.T., Hannay, Y., Pfahl, D., Benestad, H.C. and Langtangen, H.P. (2011), "Literature review of agile practices and their effects in scientific software development", Proceedings of the 4th International Workshop on Software Engineering for Computational Science and Engineering, pp. 1-9, doi: 10.1145/1985782.1985784.

Stehr, N. (1994), Knowledge Societies. The Transformation of Labour, Property and Knowledge in Contemporary Society, Sage, London.

Stiegler, B. (2014), Digital Studies: organologie Des Savoirs et Technologies de la Connaissance, FYP Editions, Paris. 
JWL 34,1

Strohmeier, D.E.P. and Parry, S. (2014), "HRM in the digital age - digital changes and challenges of the HR profession”, Employee Relations, Vol. 36 No. 4, doi: 10.1108/ER-03-2014-0032.

Suchman, L. (1987), Plans and Situated Action: The Problem of Human-Machine Communication, Cambridge University Press, Cambridge.

Thompson, J.D. (1967), Organization in Action, McGraw-Hill, New York, NY.

Tranfield, D., Denyer, D. and Smart, P. (2003), "Towards a methodology for developing evidenceinformed management knowledge by means of systematic review", British Journal of Management, Vol. 14 No. 3, pp. 207-222.

Tsoukas, H. (1989), "The validity of idiographic research explanations", Academy of Management Review, Vol. 14 No. 4, pp. 551-561.

Tsoukas, H. (2009), "Craving for generality and small-N studies: a wittgensteinian approach towards the epistemology of the particular in organization and management studies", in Buchanan, D.A. and Bryman, A. (Eds), The Sage Handbook of Organizational Research Methods, Sage, London, pp. 285-301.

Warr, P. and Bunce, D. (1995), “Trainee characteristics and the outcomes of open learning”, Personnel Psychology, Vol. 48 No. 2, pp. 347-375.

Wenger, E. (1998), Communities of Practice: Learning, Meaning, and Identity, Cambridge University Press, Cambridge.

Yoon, S.W., Song, J.H., Lim, D.H. and Joo, B.K. (2010), "Structural determinants of team performance: the mutual influences of learning culture, creativity and knowledge", Human Resource Development International, Vol. 13 No. 3, pp. 249-264.

\section{Further reading}

Frey, C.B. and Osborne, M.A. (2017), "The future of employment: how susceptible are jobs to computerization", Technological Forecasting and Social Change, Vol. 114, pp. 254-280.

Hecklau, F., Galeitzke, M., Flachs, S. and Holger, K. (2017), "Human resources management: MetaStudy-Analysis of future competences in industry 4.0", In ECMLG2017 13th European Conference on management, leadership and Governance: ECMLG 2017, Academic Conferences and publishing limited, p. 163.

March, J.G. (1991), "Exploration and exploitation in organizational learning", Organization Science, Vol. 2 No. 1, pp. 71-78.

Newell, S., Robertson, M., Scarbrough, M. and Swan, N. (2009), Managing Knowledge Work and Innovation, Second edition, Palgrave Macmillan.

Yin, R.K. (2011), Applications of Case Study Research, Sage, London.

Corresponding author

Silvia Ivaldi can be contacted at: silvia.ivaldi@unibg.it

For instructions on how to order reprints of this article, please visit our website:

www.emeraldgrouppublishing.com/licensing/reprints.htm

Or contact us for further details: permissions@emeraldinsight.com 